\title{
Invasive coronary imaging in animal models of atherosclerosis
}

\author{
N. S. van Ditzhuijzen • M. van den Heuvel • O. Sorop • R. W. B. van Duin • \\ I. Krabbendam-Peters • R. van Haeren • J. M. R. Ligthart • K. T. Witberg • \\ D. J. Duncker • E. Regar • H. M. M. van Beusekom • W. J. van der Giessen
}

Published online: 9 September 2011

(C) The Author(s) 2011. This article is published with open access at Springerlink.com

Experimental disease models have enhanced our understanding of the pathogenesis of atherosclerosis development. For example, insight has been gained into the role of the endothelium, lipids, platelets and inflammation, as well as into potential diagnostic and therapeutic interventions. Moreover, transgenic and knock-out technologies have become a widespread approach and this is a growing field to assess the role of individual genes in vascular biology and pathology. However, atherosclerosis is most of all a multifactorial disease, influenced by a multitude of environmental factors. Therefore, it is important to also study non-transgenic animal models that closely resemble the human situation with atherosclerotic lesions at anatomical locations that mimic the clinical manifestation of the disease, e.g. coronary artery disease (CAD). Although no model completely mimics

Nienke S. van Ditzhuijzen and Mieke van den Heuvel contributed equally to the manuscript

N. S. van Ditzhuijzen · M. van den Heuvel • O. Sorop •

R. W. B. van Duin - I. Krabbendam-Peters $\cdot$ R. van Haeren

J. M. R. Ligthart $\cdot$ K. T. Witberg • D. J. Duncker $(\bowtie) \cdot$ E. Regar

H. M. M. van Beusekom • W. J. van der Giessen

Department of Cardiology, Thoraxcenter,

Cardiovascular Research School (COEUR),

Erasmus University Medical Center,

Dr. Molewaterplein 50-60,

3015 GE Rotterdam, the Netherlands

e-mail: d.duncker@erasmusmc.nl

M. van den Heuvel

Department of Internal Medicine,

Erasmus University Medical Center,

Rotterdam, the Netherlands

N. S. van Ditzhuijzen · M. van den Heuvel • O. Sorop •

W. J. van der Giessen

Interuniversity Cardiology Institute of the Netherlands (ICIN-KNAW),

Catharijnesingel 52,

3511 GC Utrecht, the Netherlands human atherosclerosis, much can be learned from existing models in the study of this disease, also with respect to the development of new interventions. Here, we describe the most relevant animal models of atherosclerosis, while focusing on CAD development and the use of coronary diagnostic and therapeutic interventions. In addition, we show examples of features of a large animal model of CAD including pictures of invasive coronary imaging.

\section{Small versus large animal models}

Small animal models, primarily small rodents and rabbits, have been used extensively in atherosclerosis research. Some of the reasons include low costs, availability, and easy usability (Table 1). However, mice do not spontaneously develop atherosclerosis without genetic manipulation since they have a lipid profile that is different from humans. Yet, due to genetic modification and cross-breeding specific strains can be generated and used to unravel molecular mechanisms involved in the atherosclerosis process [1]. However transgenic mouse models do not typically develop advanced lesions, including plaque rupture and thrombosis [2], which is typical in patients presenting with symptomatic disease. When size becomes more important, small animal models need to be complemented by larger animal models in which vessel characteristics are more similar to human arteries. The rabbit model on a high cholesterol diet has been widely used in the study of experimental atherosclerosis (Table 1). Combined with arterial wall injury, lesions at least partly resembling human plaque will develop in the aorta or iliac arteries of this model [3]. However, when coronary atherosclerosis is the object of study, pigs seem to be the most representative model (Table 1). Pigs have a highly similar anatomy and 
Table 1 Animal models of atherosclerosis

\begin{tabular}{|c|c|c|}
\hline Animal model & Advantages & Limitations \\
\hline Mouse & $\begin{array}{l}1 \text { Rapid development of atherosclerotic plaque } \\
2 \text { Short reproductive cycle+large litters } \\
3 \text { Well-known genome+genome manipulation possible } \\
4 \text { Cheap }\end{array}$ & $\begin{array}{l}1 \text { Limited resemblance to humans } \\
2 \text { Limited complex atherosclerotic lesion formation } \\
3 \text { Very high levels of blood lipids + different lipid profile }\end{array}$ \\
\hline Rat & $\begin{array}{l}1 \text { Useful as restenosis model } \\
2 \text { Cheap }\end{array}$ & 1 No development of atherosclerotic lesions \\
\hline Rabbit & $\begin{array}{l}1 \text { Fibroatheroma lesions } \\
2 \text { Useful as restenosis model } \\
3 \text { Affordable }\end{array}$ & $\begin{array}{l}1 \text { Need for high plasma cholesterol levels to develop atherosclerosis } \\
2 \text { No plaque rupture model } \\
3 \text { Model for neointima formation }+ \text { re-endothelialisation rather than } \\
\text { atherosclerosis } \\
4 \text { Coronary evaluation difficult }\end{array}$ \\
\hline Pig & $\begin{array}{l}1 \text { Atherosclerotic lesions similar to human disease } \\
2 \text { Blood lipids in human range } \\
3 \text { Invasive coronary imaging possible } \\
4 \text { Useful as restenosis model post-intervention } \\
5 \text { Useful for detailed coronary endothelial function studies }\end{array}$ & $\begin{array}{l}1 \text { Expensive } \\
2 \text { Difficult to handle due to size } \\
3 \text { Limited genomic tools }\end{array}$ \\
\hline Monkey & $\begin{array}{l}1 \text { Atherosclerotic lesions similar to human disease } \\
2 \text { Influence of behavioural factors, e.g. psychosocial } \\
\text { stress } \\
3 \text { Influence of hormonal status }\end{array}$ & $\begin{array}{l}1 \text { Ethical concerns } \\
2 \text { Very expensive } \\
3 \text { Difficult to handle }\end{array}$ \\
\hline
\end{tabular}

physiology of the coronary system as compared to humans [4]. In addition, with use of toxin-mediated pancreatic damage and a high fat diet, human diabetes mellitus (DM)-like metabolic alterations will develop [5], followed by coronary lesions resembling the human condition closely with even some characteristics of vulnerable plaque [6, 7]. Historically monkeys have also been considered to be a good model of human atherosclerosis (Table 1); in particular the effects of hormones and the role of behaviour can be studied with this model [8,9]. However, nowadays monkeys are not widely used due to obvious species-specific ethical concerns and costs [2].

In the validation process of coronary interventional devices and therapies for diagnosis and treatment of human CAD, both healthy rabbit [10] and pig models [11] have been used extensively, although the rat model has also been used occasionally [12] (Table 1). In these models, arterial overstretch injury with stenting will result in a restenosis process with re-endothelialisation, inflammation and neointima formation. However, these are healthy animal models in which the vascular healing response occurs faster than in diseased humans [10, 11]. Therefore, the USA Food and Drug Administration has proposed a guidance that new coronary diagnostic and therapeutic interventional devices need to be tested in more clinically relevant animal models of disease (6255companion.doc, 2008). Since the porcine model is
Table 2 Plasma characteristics

\begin{tabular}{lccc}
\hline Plasma markers & Diabetic pigs & $\begin{array}{l}\text { Non-diabetic } \\
\text { pigs }\end{array}$ & $\begin{array}{l}\text { Two-way } \\
\text { ANOVA }\end{array}$ \\
\hline $\begin{array}{l}\text { Glucose (mmol/l) } \\
9 \text { months }\end{array}$ & $15 \pm 2.9^{*}$ & $4.1 \pm 0.27$ & $P<0.01^{\mathrm{a}}$ \\
12 months & $13 \pm 2.3^{*}$ & $4.5 \pm 0.47$ & \\
15 months & $18 \pm 4.5^{*}$ & $5.1 \pm 0.42$ & \\
Triglycerides (mmol/1) & & & \\
9 months & $1.15 \pm 0.26$ & $0.64 \pm 0.27$ & \\
12 months & $0.95 \pm 0.25$ & $0.44 \pm 0.08$ & \\
15 months & $1.26 \pm 0.50$ & $0.64 \pm 0.19$ & \\
Cholesterol (mmol/l) & & & \\
9 months & $20 \pm 2.0$ & $20 \pm 2.6$ & \\
12 months & $18 \pm 1.8$ & $19 \pm 2.0$ & \\
15 months & $17 \pm 1.7$ & $18 \pm 2.7$ & \\
LDL cholesterol (mmol/l) & $17 \pm 1.9$ & $16 \pm 2.2$ & \\
9 months & $15 \pm 1.6$ & $15 \pm 1.9$ & \\
12 months & $14 \pm 1.7$ & $15 \pm 2.5$ & \\
15 months & $5.2 \pm 0.22$ & $5.8 \pm 0.21$ & \\
HDL cholesterol (mmol/l) & $5.7 \pm 0.31$ & \\
9 months & $5.7 \pm 0.31$ & $5.7 \pm 0.35$ & \\
12 months & $5.1 \pm 0.40$ & & \\
15 months & & & \\
\hline
\end{tabular}

Values are mean \pm SEM,

${ }^{*} P<0.05$ diabetic vs. non-diabetic pigs at corresponding time points, ${ }^{a}$ diabetic vs. non-diabetic pigs over time

$L D L$ low density lipoprotein, $H D L$ high density lipoprotein 
the only model in which CAD can be truly studied and catheters and coronary interventional devices can be applied to the vascular bed they are designed for, this model might be considered the most suitable [13]. New types of invasive coronary imaging techniques have already been applied in the pig model, e.g. optical coherence tomography (OCT) in healthy porcine coronaries [14] and intravascular ultrasound (IVUS) in diseased porcine coronaries [7].

Present animal model

In light of the considerations outlined above, the present study was undertaken to investigate coronary atherosclerosis development over time with the use of a diseased porcine model.
The study was performed in accordance with the Guide for the Care and Use of Laboratory Animals (NIH Publication No. 85-23, revised 1996), and with approval of the Erasmus MC Animal Care committee. For this purpose, diabetes was induced in a subgroup of male crossbred (Yorkshire $\mathrm{x}$ Landrace) pigs by single dose injection of streptozotocin $(140 \mathrm{mg} / \mathrm{kg})$ to give a subtotal destruction of pancreatic betacells, as described previously [5]. After 2 weeks of stable DM induction, a high fat atherogenic diet was introduced to all pigs. The pigs (diabetic: $n=8$; non-diabetic: $n=7$ ) were adjusted to this diet and followed up to study atherosclerosis development over time up to 15 months. Similar growth patterns were achieved in all pigs via adjustment of individual caloric intake. Moreover, blood glucose levels were monitored in diabetic pigs and insulin therapy was
Fig. 1 Typical example of the development of an atherosclerotic plaque over time on OCT and IVUS in a diabetic pig; a OCT of intimal hyperplasia at 9 months $(*)$; $\mathbf{b}$ IVUS of the same cross section as shown in a fails to clearly detect the early lesion; $\mathbf{c}+\mathbf{d}$ OCT and IVUS of the growing plaque at 12 months $(*)$; $\mathbf{e}+\mathbf{f}$ OCT and IVUS of the same growing plaque at 15 months $(*)$
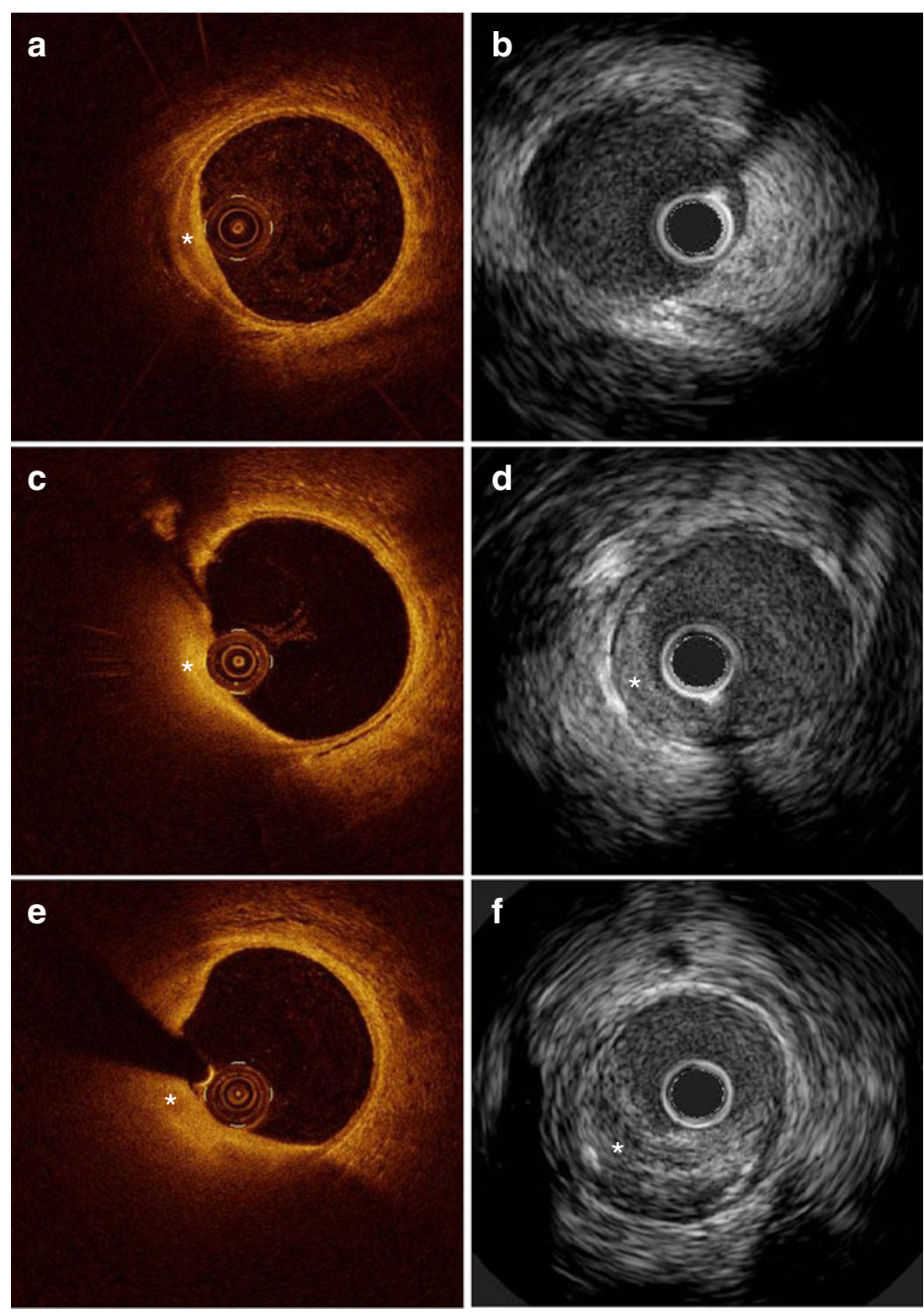
started only when plasma ketones appeared, to prevent severe DM-related complications. Anaesthetised pigs were imaged at 9, 12 and 15 months of study duration by two invasive coronary imaging modalities. Moreover, arterial blood samples were taken at these time points. A subgroup of pigs $(n=5)$ was sacrificed at 12 months, the remaining animals $(n=10)$ at 15 months to obtain coronary tissue for histology. Afterwards, plasma concentrations of glucose, total cholesterol, and low and high density lipoprotein (LDL and HDL) cholesterol were measured at the clinical chemical laboratory of the Erasmus MC using standard protocols.

\section{Imaging modalities}

Two invasive coronary imaging modalities were used in the present study: OCT and gray-scale IVUS. OCT, using an infrared light source, has an imaging depth of approximately $1.5 \mathrm{~mm}$ into tissue, an axial resolution of $10-15 \mu \mathrm{m}$ and a lateral resolution of $25-40 \mu \mathrm{m}$. This image resolution of OCT offers the potential to assess coronary atherosclerosis in detail $[15,16]$. Evaluation of atherosclerosis by OCT was performed in vivo in all pigs at 9, 12 and 15 months using the C7 XR Fourier-Domain OCT system (St. Jude Medical, Westford, MA, USA). Cross-sectional images were acquired at 100 frames per second with an automatic pullback speed of $20 \mathrm{~mm} / \mathrm{s}$.

The limited penetration depth of OCT is a shortcoming for the assessment of the total vessel wall, particularly in case of a diseased vessel. Therefore, in case of a plaque thickness $>1.5 \mathrm{~mm}$, evaluation of the plaque was done by gray-scale IVUS using an automated pullback speed of $0.5 \mathrm{~mm} / \mathrm{s}$ (Atlantis SR Pro, Boston Scientific
Corp., Natick, MA, USA). During pullback acquisition, images were obtained at a rate of 30 frames/s. This technique, using sound instead of light, has an axial resolution of 80 $200 \mu \mathrm{m}$ and a lateral resolution of $200-400 \mu \mathrm{m}$. The penetration depth is $4-8 \mathrm{~mm}$, which permits visualisation of the total vessel wall and therefore precise assessment of the extent of atherosclerosis within a segment of a coronary artery [17].

\section{Preliminary results}

In diabetic pigs, plasma glucose levels were elevated at every measured time point as compared with the nondiabetic pigs (Table 2, $P<0.05$ ). Moreover in this group of pigs, plasma triglycerides were increased over time (Table $2, P<0.05$ ) as well. Since both groups were fed an atherogenic diet, both showed elevated total cholesterol, LDL and HDL levels, which were not different over time (Table 2). In summary, diabetic pigs showed human-like DM characteristics of hyperglycaemia and triglyceridaemia, whereas all pigs showed evidence of hypercholesterolaemia.

These metabolic alterations were accompanied by coronary atherosclerosis development. Indeed, at 9 months small early lesions could be detected in the coronary arteries of most pigs, specifically seen with OCT imaging (Fig. 1a). With IVUS this early stage of atherosclerosis was not visible (Fig. 1b). Over time (12 and 15 months), these lesions showed progression, both in size and in quantity as exemplified with OCT and IVUS (Fig. 1c - f). Histology at 12 months confirmed the formation of more complex coronary atherosclerosis at this time point, consisting of lipid accumulation and calcification also seen on IVUS (Fig. 2a - c). All pigs
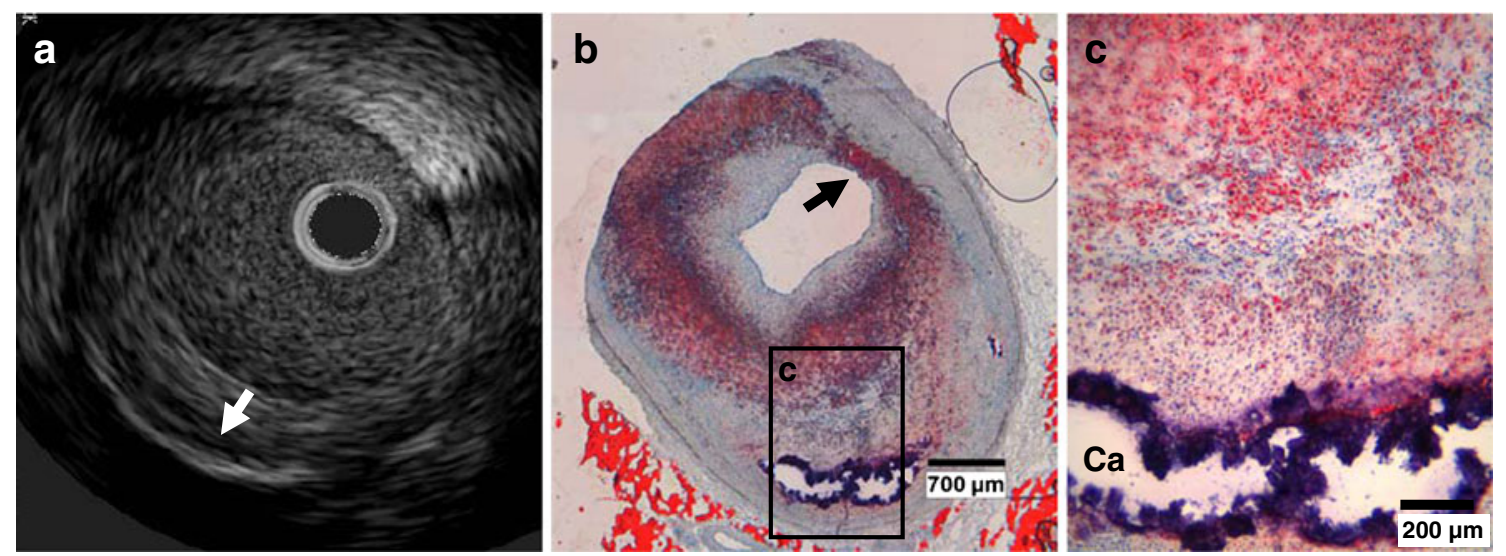

Fig. 2 Typical example of IVUS (a) and histology (b, c) of a coronary atherosclerotic plaque in a diabetic pig. a IVUS of the same plaque as seen in $\mathbf{b}$ and $\mathbf{c}$ with deep calcium (white arrow). $\mathbf{b}$ and $\mathbf{c}$ show an overview and detail of the plaque with circumferential lipid accumulation (stained red) and deep calcification $(\mathrm{Ca}$, remaining rim stained blue). The coronary plaque even shows the presence of a thin fibrous cap (black arrow) overlying the superficial lipid-rich tissue, showing a likeness to a thin cap fibrous atheroma [18]. Oil-red-O stain, bar in $\mathbf{b}$ is $700 \mu \mathrm{m}$, bar in $\mathbf{c}$ is $200 \mu \mathrm{m}$ 
were sacrificed at 15 months because of the attained body weight and related handling difficulties (diabetic vs. non-diabetic: $97 \pm 3$ vs. $96 \pm 1 \mathrm{~kg}$ ).

\section{Conclusion}

Different animal models are useful to study different aspects in the process of atherosclerosis development (Table 1). However, for the study of CAD and related diagnostic and therapeutic interventions, a porcine disease model seems most suitable. In the presence of several metabolic alterations, lesions develop within 9 to 12 months, closely resembling human coronary atherosclerotic plaques upon examination by histology.

In addition, examples from this model show that OCT and gray-scale IVUS appear to be highly complementary imaging modalities for the evaluation of the development of coronary atherosclerotic plaque over time. The present preliminary results indicate that these modalities can be used for plaque characterisation in vivo, making this large diseased animal model ideal for studying new coronary diagnostic and therapeutic interventions.

Acknowledgement The article is dedicated to Professor Dr. W.J. van der Giessen who sadly passed away in June 2011.

Open Access This article is distributed under the terms of the Creative Commons Attribution Noncommercial License which permits any noncommercial use, distribution, and reproduction in any medium, provided the original author(s) and source are credited.

\section{References}

1. Bentzon JF, Falk E. Atherosclerotic lesions in mouse and man: is it the same disease? Curr Opin Lipidol. 2010;21 (5):434-40

2. Badimon L. Atherosclerosis and thrombosis: lessons from animal models. Thromb Haemost. 2001;86(1):356-65.

3. Aikawa M, Sugiyama S, Hill CC, et al. Lipid lowering reduces oxidative stress and endothelial cell activation in rabbit atheroma. Circulation. 2002;106(11):1390-6.
4. Duncker DJ, Bache RJ. Regulation of coronary blood flow during exercise. Physiol Rev. 2008;88(3):1009-86.

5. Koopmans SJ, Mroz Z, Dekker R, et al. Association of insulin resistance with hyperglycemia in streptozotocindiabetic pigs: effects of metformin at isoenergetic feeding in a type 2-like diabetic pig model. Metabolism. 2006;55(7):96071.

6. Gerrity RG, Natarajan R, Nadler JL, et al. Diabetes-induced accelerated atherosclerosis in swine. Diabetes. 2001;50 (7):1654-65.

7. Chatzizisis YS, Jonas M, Coskun AU, et al. Prediction of the localization of high-risk coronary atherosclerotic plaques on the basis of low endothelial shear stress: an intravascular ultrasound and histopathology natural history study. Circulation. 2008;117 (8):993-1002.

8. Clarkson TB, Mehaffey MH. Coronary heart disease of females: lessons learned from nonhuman primates. Am J Primatol. 2009;71 (9):785-93.

9. Shively CA, Musselman DL, Willard SL. Stress, depression, and coronary artery disease: modeling comorbidity in female primates. Neurosci Biobehav Rev. 2009;33(2):133-44.

10. Nakazawa G, Finn AV, Ladich E, et al. Drug-eluting stent safety: findings from preclinical studies. Expert Rev Cardiovasc Ther. 2008;6(10):1379-91.

11. van den Heuvel M, Sorop O, Batenburg WW, et al. Specific coronary drug-eluting stents interfere with distal microvascular function after single stent implantation in pigs. JACC Cardiovasc Interv. 2010;3(7):723-30

12. Langeveld B, Roks AJ, Tio RA, et al. Rat abdominal aorta stenting: a new and reliable small animal model for in-stent restenosis. J Vasc Res. 2004;41(5):377-86.

13. Granada JF, Kaluza GL, Wilensky RL, et al. Porcine models of coronary atherosclerosis and vulnerable plaque for imaging and interventional research. EuroIntervention. 2009 May;5(1):140-8.

14. Tearney GJ, Jang IK, Kang DH, et al. Porcine coronary imaging in vivo by optical coherence tomography. Acta Cardiol. 2000;55 (4):233-7.

15. Yabushita H, Bouma BE, Houser SL, et al. Characterization of human atherosclerosis by optical coherence tomography. Circulation. 2002;106(13):1640-5.

16. Regar E, van Soest G, Bruining N, et al. Optical coherence tomography in patients with acute coronary syndrome. EuroIntervention. 2010;6(Suppl G):G154-60.

17. Mintz GS, Nissen SE, Anderson WD, et al. American College of Cardiology Clinical Expert Consensus Document on Standards for Acquisition, Measurement and Reporting of Intravascular Ultrasound Studies (IVUS). A report of the American College of Cardiology Task Force on Clinical Expert Consensus Documents. J Am Coll Cardiol. 2001;37(5):1478-92.

18. Virmani R, Burke AP, Farb A, et al. Pathology of the vulnerable plaque. J Am Coll Cardiol. 2006;47(8 Suppl):C13-8. 